\title{
Post-mortem Findings and Causes of Death of Harbour Porpoises (Phocoena phocoena) Stranded from 1990 to 2000 along the Coastlines of Belgium and Northern France
}

\author{
T. Jauniaux, D. Petitjean, C. Brenez, M. Borrens, L. Brosens, \\ H. Haelters*, T. Tavernier $\dagger$ and F. Goignoul \\ Department of Pathology, Veterinary College, University of Liège, B43, 4000 Liège; *Management Unit of the North Sea \\ Mathematical Models, Royal Belgian Institute of Natural Sciences, Gulledelle 100, 1200 Brussels; and $\dagger$ Royal Belgian \\ Institute of Natural Sciences, Vautierstraat 29, 1000 Brussels, Belgium
}

\begin{abstract}
Summary
Between the years 1990 and 2000, an attempt was made to determine the causes of death of 55 harbour porpoises stranded along the Belgian and northern French coasts. From 1990 to 1996, only five carcasses were collected as against seven in 1997, eight in 1998, 27 in 1999 and eight in 2000. The sex ratio was normal and most of the animals were juvenile. The most common findings were emaciation, severe parasitosis and pneumonia. A few cases of fishing net entanglement were observed. The main microscopical lesions were acute pneumonia, massive lung oedema, enteritis, hepatitis and gastritis. Encephalitis was observed in six cases. No evidence of morbillivirus infection was detected. Pneumonia was associated with bacteria or parasites, or both. The causes of death and the lesions were similar to those previously reported in other countries bordering the North Sea. The cause of the increased numbers of carcasses in 1999 was unclear but did not include viral epizootics or net entanglement. A temporary increase in the porpoise population in the southern North Sea may have been responsible.

(C) 2002 Harcourt Publishers Ltd
\end{abstract}

\section{Introduction}

The multidisciplinary research group MARIN (Marine Animals Research and Intervention Network) deals with marine mammal strandings along the coasts of Belgium and Northern France (Fig. 1). Its aims are to identify the causes of death and monitor the health status of marine mammals. This work includes determining concentrations of chemical contaminants in tissues and relating lesions to toxicological data and human activities such as navigation and commercial fishing. Indeed, the North Sea is heavily exposed to contaminants such as heavy metals and organochlorines, which accumulate in predatory marine mammals (Siebert et al., 1999).

Harbour porpoises (Phocoena phocoena) are the most common cetaceans in the North Sea, being widely distributed across the northern and the central parts, but much less so in the southern part (Northridge et al., 1995). In the southern part, the distribution follows a seasonal variation, porpoises being abundant in coastal waters during winter while in the summer they frequent the Dogger Bank (Reijnders et al., 1996). During the 20th century, the porpoise population has severely declined along the coasts of the southern North Sea (Addink and Smeenk, 1999), probably due to pollution, entanglement in fishing gear and alterations in food supply.

The most frequent causes of death of North Sea porpoises are "by-catching" (accidental catching) in fishing gear and acute bronchopneumonia (Baker and Martin, 1992; Kuiken et al., 1994; Kirkwood et al., 1997). In the early 1990s, a few cases of 


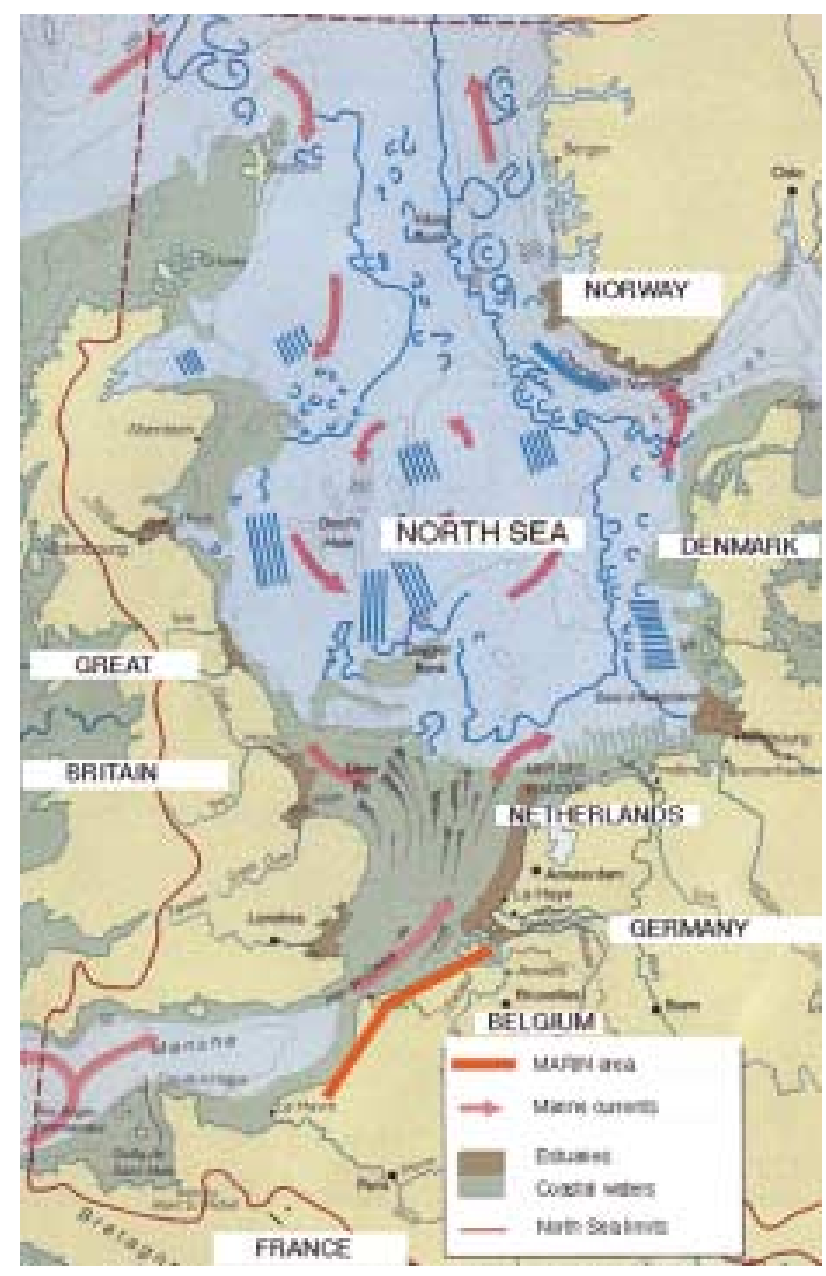

Fig. 1. Coastline covered by the Marine Animals Research and Intervention Network in the southern North Sea (MARIN area), from the Scheldt estuary to the bay of the Somme.

morbillivirus infection were described (Kennedy et al., 1991, 1992a). However, this disease has not been reported subsequently in the North Sea (Jepson et al., 2000; Siebert et al., 2001). Nevertheless, specific antibodies were detected in $10 \%$ and $88 \%$ of porpoises from British (van Bressem et al., 1998) and German waters (Müller et al., 2000), respectively, indicating the persistence of morbillivirus infection in these populations (Müller et al., 2000).

The aims of this study were to describe the lesions and causes of death of harbour porpoises stranded along the Belgian and Northern France coastlines between 1990 and 2000, mainly after 1996.

\section{Material and Methods}

\section{Collection of Animals}

Between 1990 and 2000, strenuous efforts were made to collect stranded or by-caught harbour porpoises along the Belgian coast. In addition, porpoises from the coast of northern France (from the Belgian border to the Bay of the Somme) were collected between 1995 and 2000. Carcasses were forwarded to the Department of Veterinary Pathology of the University of Liège. Three age categories based on body length were recognized: neonatal $(\leq 90 \mathrm{~cm})$, immature $(91-130 \mathrm{~cm})$ and mature $(>130 \mathrm{~cm})$ (Lockyer, 1995).

\section{Necropsy and Samples}

In total, 55 porpoises were subjected to necropsy and sampled by a standard procedure (Kuiken and García Hartmann, 1991). Briefly, the porpoises were measured and weighed, and the blubber thickness was measured at the caudal insertion of the dorsal fin. After external examination, the abdominal and thoracic cavities were opened and the skull was sawn longitudinally to expose the brain.

For histopathology, samples of eye, skin, liver, lymph nodes, gonad, reproductive tract, oesophagus, stomach, intestine, kidney, urinary bladder, pancreas, lung, heart, thyroid, thymus and brain, and all tissues with lesions, were fixed in $10 \%$ buffered formalin and embedded in paraffin wax by routine procedures. Sections $(5 \mu \mathrm{m})$ were cut and stained with haematoxylin and eosin (HE). Selected sections were also stained with Masson trichrome, periodic acid-Shiff (PAS) for fungi and Ziehl-Neelsen stain for acid-fast organisms. In addition, immunohistochemical examination with a monoclonal antibody against the glycosylated haemagglutinin protein of phocine distemper virus (clone 1.3) (Trudgett et al., 1991; Domingo et al., 1992) was performed on sections of lungs, pulmonary lymph nodes and all lesions suspected to have a viral origin. The other immunohistochemical reagents used were those included in the Enhanced Polymer One-Step Staining Procedure (Dako Envision ${ }^{\mathrm{TM}}$; Dako, Glostrup, Denmark) (Jauniaux et al., 2000).

For bacteriology, tissue samples were collected aseptically and incubated under aerobic and anaerobic conditions on Columbia blood agar containing sheep blood 5\% (Becton Dickinson Europe, Meylan Cedex, France) and on a selective medium for Enterobacteriaceae (Gassner agar; Oxoid, Gent, Belgium).

Blood samples were collected and examined for 


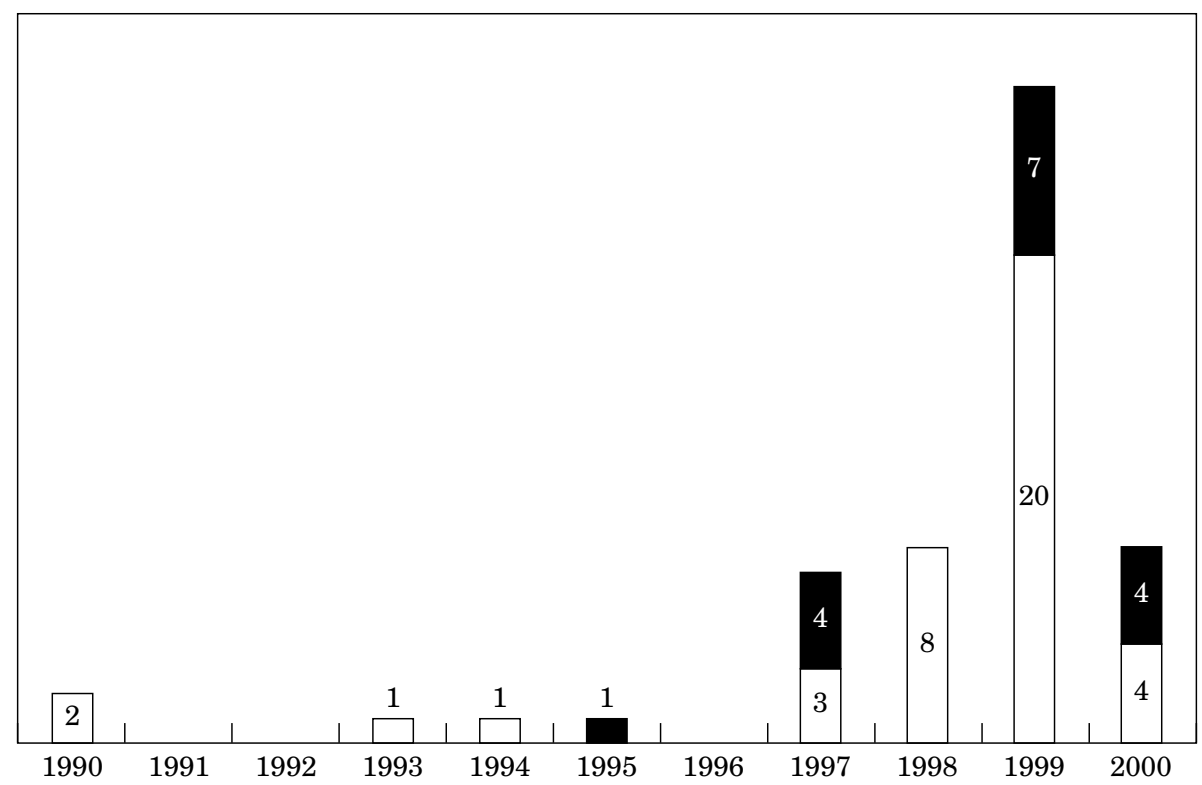

Fig. 2. Annual distribution of porpoises found stranded along the coast of Belgium and northern France between 1990 and 2000. White column, coast of Belgium; black column, coast of northern France.

the presence of antibodies against Brucella abortus (Tryland et al., 1999) and canine distemper virus (CDV) (Appel and Robson, 1973).

Parasites were collected and preserved in $70 \%$ ethanol containing glycerin 5\%.

In suspected cases of viral disease, Vero cell cultures were infected as previously described for seals (Jauniaux et al., 2001).

\section{Results}

\section{Harbour Porpoises}

The 55 carcasses examined consisted of 26 nonpregnant females, 28 males, and one animal of undetermined sex, obtained from the coasts of Belgium $(n=40)$ and northern France $(n=15)$. Six porpoises were neonatal, 30 immature, 17 mature, and two of undetermined age.

The annual distribution was irregular with a major rise in the final 4 years of the study, particularly in 1999 (Fig. 2). The majority of strandings occurred during winter and early spring.

\section{Gross Pathology}

The most common findings were severe emaciation $(33 / 55)$, acute bronchopneumonia (27/55), and extended and multisystemic parasitosis (28/55). It was usual to find more than one possible cause of death in individual porpoises.
Body condition. Severe emaciation was characterized by weight loss, reduced blubber layer thickness and dorsal muscle atrophy. Mean blubber thickness for emaciated porpoises was $9 \cdot 2 \pm 3.8 \mathrm{~mm}$ and for non-emaciated porpoises $20 \cdot 1 \pm 10 \cdot 7 \mathrm{~mm}$ $(P<0 \cdot 0001)$. Blubber thickness was not associated with age or sex (data not shown).

Bronchopneumonia and other intrathoracic findings. Acute bronchopneumonia was characterized by large areas of pulmonary consolidation with haemorrhagic or purulent fluid oozing from the parenchyma. In three cases, abscesses, $0 \cdot 5-2 \mathrm{~cm}$ in diameter, with creamy yellowish-white contents were distributed throughout the lungs. Frothy fluid was frequently present in the bronchioli, bronchi and trachea, which also contained purulent, bloodstained exudate or small blood clots, or both. Most often, this finding was associated with massive infestation of the airways with the nematodes $T_{0}$ rynurus convolutus and Pseudalius inflexus, the latter parasite being firmly attached to the lung parenchyma. Small airways were frequently partly or completely occluded. Pneumonia was associated with Escherichia coli $(n=2)$, a non-haemolytic Staphylococcus sp. $(n=3)$, a haemolytic Streptococcus sp. $(n=3)$, Aeromonas hydrophyla $(n=1)$ and Proteus vulgaris $(n=1)$; all cases of Pseudomonas sp. infection $(n=4)$ were associated with an acute necrotizing pneumonia. Parasitic infestation was also present in all of these cases of bacterial infection. The 
pulmonary and bronchial lymph nodes were often enlarged and oedematous. In one case, a chronic thrombus of a pulmonary collateral artery was observed. The wall of this vessel was thickened and the lumen occluded with an adherent thrombus which had organized around nematodes.

Of the six neonates, two were considered to be stillborn since the lungs were entirely atelectatic. Another was regarded as an aborted fetus since a section of umbilical cord, $82 \mathrm{~cm}$ in length, remained attached.

Acute pleurisy with fibrinopurulent exudate was observed on the surface of the left lung of one animal. It was associated with a fistula leading to a necrotic mass $(5 \mathrm{~cm}$ in diameter) on the first rib, limited by a fibrous wall and containing bone fragments. The rib had recently been fractured, without evidence of bone repair. No lesion was observed in the overlying tissues.

Three porpoises had mild parasitic infestation of the pulmonary airways without evidence of bronchopneumonia.

Severe and extended parasitosis. This, the second most frequent observation, consisted of heavy infestations of multiple organs, with associated lesions of bronchopneumonia, chronic ulcerative gastritis and chronic hepatitis. Bronchopneumonia was associated with nematode infestations of airways and pulmonary blood vessels (P. inflexus), including pulmonary arteries and the right ventricle of the heart. In 12 cases, small nodules (3-6 $\mathrm{mm}$ in diameter) containing encapsulated nematodes, considered to be Halocercus sp., were disseminated throughout the lungs. A focal chronic pleuritis was associated with a nematode head embedded under the pleura, the body $(13 \mathrm{~cm}$ length) lying free on the dorsal surface of the lung. Chronic ulcerative gastritis was frequently associated with nematode (Anisakis simplex) infestation (14 animals). The larvae of these worms were attached to the centre of the ulcers, while adults together with some larvae were free in the gastric lumen. Usually several hundred, and in one case $>1000$, nematodes were present. The ulcers $(1-3 \mathrm{~cm}$ in diameter), which had a punched-out appearance, were associated with thickened and congested submucosa. The surrounding epithelium was irregular, rough and hyperplastic and had a papillomatous appearance in severe cases (Fig. 3). Chronic nodules $(1-2 \mathrm{~cm}$ in diameter) in the wall of the second stomach had a thick, white, fibrous capsule and a core containing trematodes (Pholeter gastrophilus). In one case, a trematode nodule at the junction of the second and third stomachs had

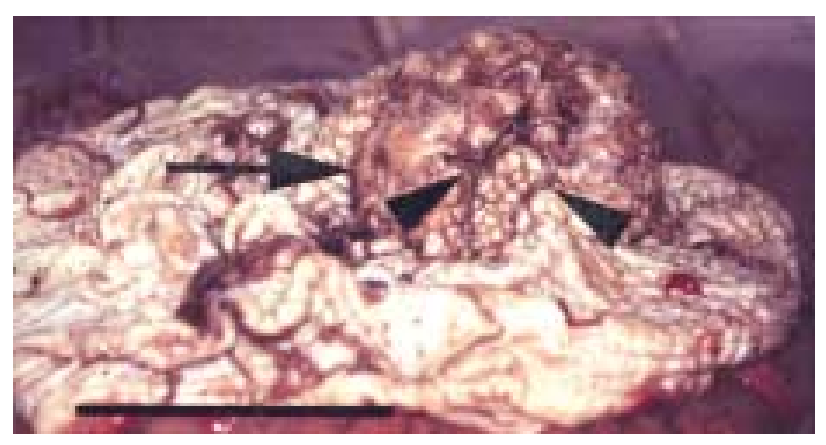

Fig. 3. Nodular and hyperplastic (arrow) chronic ulcerative gastritis associated with Ansisakis simplex infestation (arrowheads). Bar, $8 \mathrm{~cm}$.

resulted in stenosis. Extensive chronic portal hepatitis associated with fibrosis of bile ducts was observed in some cases of severe liver trematode (Campula oblonga) infestation. White septa were apparent on the liver surface, and interstitial fibrosis and thickening of bile ducts were observed in the hepatic parenchyma. Flukes were observed in these damaged bile ducts and, in some cases, in the ductus choledochus. Frequently, spherical nodules (up to $3 \mathrm{~cm}$ in diameter) with a thick, fibrous, partly calcified wall, and dark green to black caseous contents were distributed throughout the liver. Similar nodules were also observed on the pancreas (one case) and on the abdominal surface of the diaphragm (one case). Adults and larvae of Stenurus minor were observed in the middle ear of 10 porpoises (out of 20 animals examined) but were not associated with gross lesions. Intestinal tape worms, identified as Diphyllobothrium sp., were observed in four cases, without lesions.

By-catch. By-catch in fishing nets was considered to be the cause of death in eight porpoises. Of these, four were incontrovertible by-catches (one being trapped in a bottom set gill net), while the others were suspected of having been discarded after capture. All of these animals were in good nutritional condition, without evidence of severe disease. However, they all had extensive pulmonary congestion and oedema, abundant white, often blood-tinged froth within airways, subcutaneous haemorrhages and recent skin lacerations. One known by-catch was considered to have been trapped after death, as indicated by post-mortem skin lacerations, thin blubber $(8 \mathrm{~mm})$ and evidence of acute bronchopneumonia.

Cutaneous findings. Cutaneous ulcers $(0 \cdot 5-4 \mathrm{~cm}$ in diameter) were observed in 12 porpoises, some 


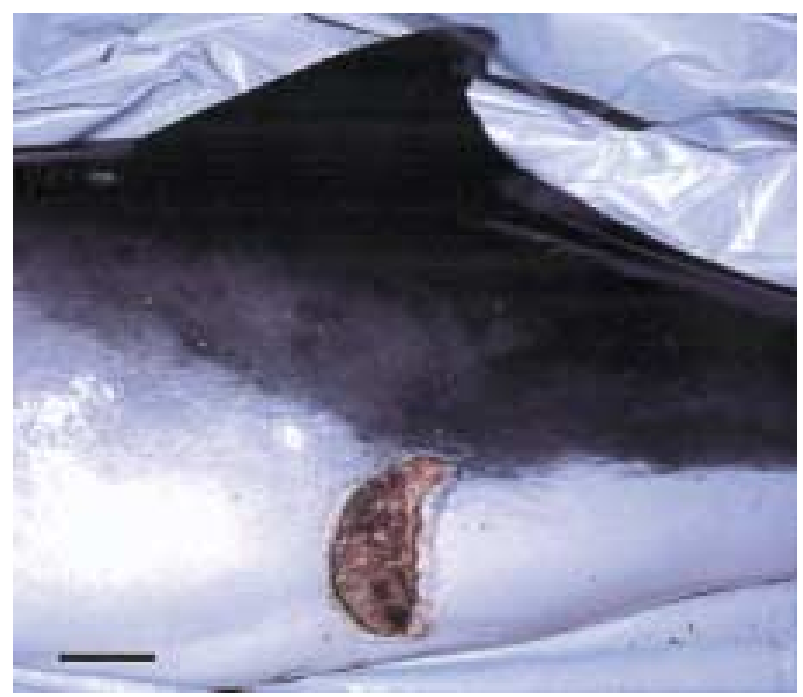

Fig. 4. Large skin ulcer on the caudal peduncle extending into muscles. Bar, $8 \mathrm{~cm}$.

being acute, and some covered by white necrotic membranes. Chronic ulcers had a thick irregular border and rough papillary centre. Two cases of severe skin ulceration were associated with a heavy infestation of copepods (Isocyamus delphini). In two animals, the ulcers were large and associated with a severe skin erosion $(5-12 \mathrm{~cm})$, extending down to the skeletal muscle (Fig. 4). One porpoise had numerous round pustules $(2-3 \mathrm{~cm}$ in diameter) on the skin of the caudal peduncle, containing yellowish-white creamy pus. White to grey spots $(1-3.5 \mathrm{~cm}$ in diameter), limited by a grey to black border, were observed on the skin of the head or distributed over the body of six animals.

Gastro-intestinal findings. Acute to chronic ulcers, varying in size from $0.5 \times 0.1$ to $4 \times 0.5 \mathrm{~cm}$, were observed in the oesophagus of six porpoises. Five to 10 ulcers were usually present around the larynx or along the cranial third of the oesophagus (Fig. 5 ). Acute ulcers were frequently covered by white fibrinous membranes overlying a congested submucosa. In one case, hundreds of small longitudinal erosions and ulcers were distributed along the entire length of the oesophagus. In three other porpoises, the oesophageal mucosa had hyperplastic foci characterized by raised epithelial plaques, 3-5 $\mathrm{mm}$ in diameter. In one case, Candida lipolytica was isolated from acute perilaryngeal ulcers.

Acute ulcerative stomatitis was seen in six cases. Numerous round or elongated acute ulcers were present on the palate, tongue or gingiva, some being covered with a fibrinous membrane. A few palatine or gingival ulcers extended down to the



Fig. 5. Dorsal view of larynx: acute ulcerative oesophagitis; ulcers (arrows) covered by fibrinous membranes. Bar, $4 \mathrm{~cm}$.

submucosal connective tissue. Acute enteritis, diagnosed in five porpoises, was associated with hyperaemia of the serosal membrane and intraluminal haemorrhagic exudate.

In one case of severe acute peritonitis, $500 \mathrm{ml}$ of fibrinohaemorrhagic exudate were present in the abdominal cavity and extensive fibrinous membranes adhered to the abdominal viscera. A small segment of the intestine and epiploon were dark red to black, suggesting an intestinal infarct. This lesion was considered to have resulted from intestinal volvulus.

The gastro-intestinal tract was empty, with no evidence of recent feeding, in 40 animals and contained fresh prey or otoliths in eight cases, the remaining seven not being examined. Some animals showed mild parasitic infestation of the gastric cavity (six cases), intestines (four cases) and bile ducts (two cases), without associated lesions.

Other findings. One porpoise showed signs of pyaemia, with small abscesses (1-2 $\mathrm{mm}$ in diameter) distributed throughout the liver, kidney and myocardium, while large abscesses were present in the lung in association with the chronic thrombus described above. Streptococcus equisimilis was isolated from the blood, brain and pulmonary lesions.

One adult female had a spherical $(2 \mathrm{~cm}$ in diameter), white, homogeneous, hard mass protuding externally on the uterine cervix.

Both adrenal glands of an adult female $(172 \mathrm{~cm}$ long) were hypertrophied and contained numerous spherical $(2-10 \mathrm{~mm}$ in diameter) cysts with translucent, viscous contents. An adult male $(160 \mathrm{~cm}$ long) had approximately 20 cysts on the thymus; 


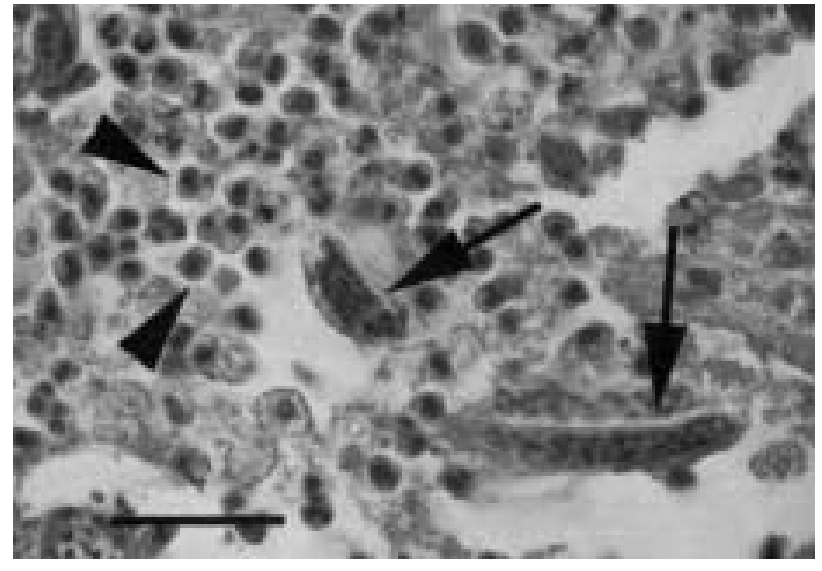

Fig. 6. Acute bronchopneumonia with neutrophils infiltration (arrowheads) around nematode larvae (arrows). HE. Bar, $120 \mu \mathrm{m}$.

these were yellowish, translucent and gelatinous, measuring $1-2 \mathrm{~cm}$ in diameter.

\section{Histopathology}

Respiratory lesions. In the lung, three major patterns of reaction were observed microscopically. Interstitial pneumonia was characterized by peribronchial lymphocytic infiltration and thickening of interalveolar septa by macrophages, lymphocytes and occasional eosinophils. In some cases, fibroplastic nodules with calcified cores were disseminated in the lung. Some bronchioles were occluded by concentric layers of hyaline membranes or by fibrous tissue entrapping eosinophils, lymphocytes and calcified areas. Frequently, an eosinophilic fluid containing macrophages filled the alveoli. Multinucleate giant cells were sometimes observed in the interstitial tissue or in the parenchyma around parasites. This first pattern of reaction was usually associated with adult nematodes in airways. The second type of reaction was a more acute lesion, characterized by neutrophilic infiltration in the parenchyma, and by exudation of fibrin, neutrophils, and erythrocytes into the airways. Haemorrhages, emphysema and atelectasis were frequently present. In severe cases, large areas of parenchymal necrosis were observed, with loss of alveolar epithelium and only alveolar septa remaining visible. Bacteria were frequently observed within the areas of necrosis. Severe alveolar reaction was more frequently observed around nematode larvae (Fig. 6). Sometimes, inflammatory exudation around nematode larvae resulted in occlusion of bronchial lumina and necrosis of bronchial walls. In two cases, large areas of necrosis were associated with vascular thrombosis.

The third lesion pattern was associated with net entrapment. In these cases, the lung was severely congested, and oedematous fluid containing erythrocytes was present in the parenchyma.

Muco-cutaneous lesions. Muco-cutaneous ulcers were usually subacute to chronic and were associated with infiltration of macrophages and fibroblasts into the underlying subcutis. A few eosinophils and evidence of neovascularization were frequently present. Areas of haemorrhage and necrosis were frequently observed in the subcutis with, in some cases, small thrombi in blood vessels. In the epithelium around the edges of ulcers, ballooning degeneration and intercellular oedema were observed, mainly in the stratum intermedium. Large intraepithelial vacuoles, with or without inflammatory cells (most frequently neutrophils), were observed near the surface. Mitotic figures were numerous in the stratum basale around ulcers. Some lingual ulcers extended to the muscle, resulting in mild myositis or muscle fibre degeneration. Few inflammatory cells were associated with oesophagal ulcers, and no evidence of inclusion bodies was observed. PAS staining was negative in all cases.

Hepatic and pancreatic lesions. The most common liver lesion was a chronic periangiocholitis associated with fluke infestation. In severe cases, fibrosis was extensive and interlobular tissue was strikingly thickened, entrapping trematode eggs and sometimes lymphocytes. Frequently, in portal areas and in nodules, bile duct proliferation was visible. In two cases, subacute hepatitis was characterized by lymphocytic infiltration into small areas of parenchymal necrosis. Two animals had subacute pancreatitis with eosinophilic infiltration around pancreatic ducts, and ductal proliferation.

Gastro-intestinal lesions. Nodules and ulcers in the first stomach were most commonly associated with nematodes, while nodules in the wall of the second gastric compartment were due to fluke infestation. Subacute to chronic ulcers of the first gastric chamber were characterized by superficial submucosal necrosis with massive infiltration by macrophages, eosinophils, fibroblasts, and scattered lymphocytes. There was evidence of neovascularization in the submucosa. Nematodes were attached to the superficial layer of the submucosa, while dead parasites, frequently surrounded by a granulomatous reaction including giant cells, were observed in the deeper layers. The epithelium around ulcers was 


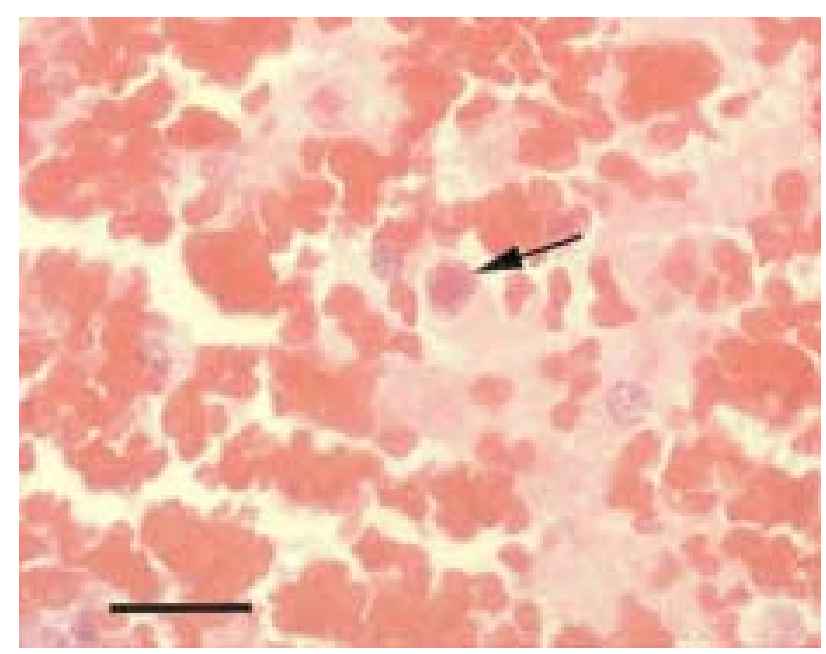

Fig. 7. Intranuclear eosinophilic inclusion (arrow) in haemorrhagic area associated with subacute granulomatous encephalitis. HE. Bar, $50 \mu \mathrm{m}$.

thickened and irregular, with severe intercellular oedema and acanthosis. The most frequent lesion in the wall of the second gastric cavity was a chronic nodular gastritis composed of successive layers of fibrous tissue in the submucosa, containing some lymphocytes and eosinophils and a core of trematodes and eggs.

Nervous and ocular lesions. Various inflammatory reactions were observed in the central nervous system of six porpoises. One case of severe subacute granulomatous encephalitis, affecting all the cerebral areas, was characterized by perivascular cuffs of macrophages and lymphocytes and large foci of haemorrhage. Areas of cerebral necrosis were massively infiltrated with macrophages. Viruslike eosinophilic intranuclear inclusion bodies (Fig. 7) were distributed throughout these lesions, but no virus was identified. A case of subacute meningoencephalitis was characterized by severe perivascular cuffs of macrophages and a few lymphocytes. A few trematode-like eggs, with thick, yellow, birefringent walls, were associated with this lesion. Three animals had a mild focal subacute encephalitis with local perivascular cuffing in the parietal or occipital cortex; in two of these cases, small necrotic foci were infiltrated by macrophages. Finally, an animal that died from pyaemia due to Streptococcus equisimilis had small abscesses distributed throughout the brain.

Perivascular cuffs of lymphocytes, plasmacytes and eosinophils were observed under the retina of two porpoises, and subretinal haemorrhage was observed in two animals with hyphaema.
Urogenital lesions. Mild to severe eosinophilic infiltration was observed in the thickened submucosa of the urinary bladder of nine porpoises.

The uterine mass (see above) in one adult female had the histological appearance of a fibroma and was composed of interlacing bundles of fibroblasts and collagen fibres, without evidence of mitotic figures.

Other lesions. Large cavitations seen in cystic adrenal glands were filled with an amorphous esosinophilic liquid.

Thymic cysts were limited by a simple squamous epithelium with intraluminal papillary projections. They had an acellular eosinophilic content. The adjacent thymic tissue was normal.

Neither immunohistochemistry nor cell culture revealed evidence of morbillivirus infection or other viral disease. Serology was negative for Brucella abortus in all porpoises tested.

\section{Discussion}

Severe emaciation, severe parasitism and bronchopneumonia were the commonest findings and fatal diseases observed were generally similar to those described in porpoises from other regions of the North Sea (Baker and Martin, 1992; Kirkwood et al., 1997; Siebert et al., 1999, 2001). However, entanglement in fishing nets was a rare cause of death in the present series, in contrast to some of the earlier studies. As reported by Siebert et al. (2001), determination of the cause of death is difficult in free-ranging wild animals, particularly cetaceans. They frequently become stranded when severely ill and several lesions, some potentially lethal, may be present simultaneously (Baker and Martin, 1992).

The blubber thickness of emaciated porpoises in this study was significantly less than in animals collected for necropsy by Lockyer (1995). On the German North Sea coast, most stranded or bycaught porpoises were in a moderate or poor nutritional state, whereas animals from the Baltic Sea were in good nutritional condition (Siebert et al., 1999, 2001). Benke et al. (1998) observed, however, that the body condition of stranded porpoises was inferior to that of by-caught animals. Siebert (1999) considered that poor nutritional status might be related to reduced food intake resulting from parasitic infection. Emaciation is not usually recorded as a fatal condition in immature or adult porpoises in British waters, starvation being described as a cause of death only in suckling animals separated 
from their mothers (Baker and Martin, 1992; Kirkwood et al., 1997). Kirkwood et al. (1997) considered that starvation might be related to wear or loss of teeth in adults. In the present study, one emaciated adult had severely worn teeth and three neonates were severely emaciated, with no evidence of milk or other food in the gastro-intestinal tract. The latter finding supports the view that separation from the mother may be a cause of death. For the 29 remaining porpoises in a poor nutritional state, emaciation compounded by other disorders, such as parasitosis and bronchopneumonia, was considered fatal. In addition, it is noteworthy that $70 \%$ of the porpoises examined had an empty gastro-intestinal tract, indicating no recent food intake. It is usual for stranded cetaceans to have an empty alimentary tract (Kennedy et al., 1991). It is possible that starvation was a consequence of ulceration of the upper gastro-intestinal tract. It might also have resulted from a decreased abundance of prey in the southern North Sea, including herring (Clupea harengus), sprat (Sprattus sprattus) and sandeel (Ammodytes sp.) (Addink and Smeenk, 1999). However, these species are still considered to be common in the area concerned.

Bronchopneumonia was frequently associated with parasitosis or emaciation, or both. These are chronic, debilitating processes which might predispose to fatal bronchopneumonia, lung parasitism often leading to secondary bacterial infection. After entanglement in fishing nets, this combination has been identified as the most frequent cause of porpoise deaths in British (Baker and Martin, 1992; Jepson et al., 2000), Dutch (García Hartmann, 1997) and German waters (Benke et al., 1998; Siebert et al., 1999, 2001). In the present study, acute bronchopneumonia was considered to be the cause of $49 \%$ of deaths, which is similar to the $46 \%$ reported in German waters but higher than the $10-12 \%$ reported in British waters.

Heavy loads of parasites are often reported in porpoises without clinical disease (Read, 1999). Nevertheless, in our study parasitism was severe, multisystemic and associated with macroscopical and microscopical lesions. Macroscopical evidence of parasitic infestation was found in the lungs of porpoises $96 \mathrm{~cm}$ or more in length. It is usual to find gross evidence of lungworm infestation in porpoises aged $7-10$ months ( $>90 \mathrm{~cm}$ in length), suggesting that they are infected after weaning through the consumption of fish (van Nie, 1989; Jepson et al., 2000), or in animals older than 1 year (Siebert et al., 2001). However, infection via the placenta or milk was suspected for Halocercus sp. by Jepson et al. (2000), who found the airways to be commonly infested by more than one parasite species; it was not possible to determine which was the most pathogenic (Jepson et al., 2000). In our investigation, lesions of bronchopneumonia were more severe around larvae than around adults, but no such difference was observed by Jepson et al. (2000). Howard et al. (1983) reported an acute reaction around larvae of Stenurus sp. but minimal inflammation associated with adults. The prevalence of lungworm infestation, $56 \%$ in our investigations, is usually high in North Sea porpoises, reaching $60 \%$ for animals stranded on the Dutch (van Nie, 1989) and German coasts (Siebert et al., 2001) and up to $69 \%$ for animals from British waters (Jepson et al., 2000). High prevalence of lungworms was also reported for by-caught animals. Disseminated abscesses associated with chronic thrombus observed in this study, is frequently reported with Pseudalius inflexus infections. Indeed, severe secondary bacterial or viral infection may develop in such cases, leading to abscessation or septicemia (Measures, 2001). Siebert et al. (2001) suggested that heavy parasitic infestation in the airways and pulmonary blood vessels reduce the ability to dive and hunt.

Anisakis simplex infestation of the first gastric compartment has frequently been associated with ulceration in stranded porpoises (Baker and Martin, 1992; Brattey and Stenson, 1995; Kirkwood et al., 1997; Siebert et al., 2001) and in other cetacean species (Sweeney and Ridgway, 1975; Baker, 1992; De Guise et al., 1995). However, this association was less frequently observed in by-caught porpoises (Brattey and Stenson, 1995). The third stage larvae of this nematode are released into the host stomach from infected fish and burrow into the mucosa and submucosa of the gastric fundus, resulting in craterlike ulcers (Howard et al., 1983). These ulcers usually have little pathological significance but may cause severe gastric haemorrhage (Kirkwood et al., 1997) or serve as a portal of entry for pathogens (Wünschmann et al., 1999b). The reported prevalence of $A$. simplex varies from $15 \%$ (van Nie, 1989) to $43 \%$ (Baker and Martin, 1992), possibly due to variations in the abundance of intermediate hosts (Baker, 1992). In the present study, 14 porpoises were severely infested and six slightly.

The prevalence of infection of the middle ear by Stenurus minor in our investigation was similar to that reported previously in by-caught (Stroud and Roffe, 1979) and stranded (van Nie, 1989; Baker and Martin, 1992) porpoises. Stroud and Roffe (1979) found no pathological changes to be associated with this nematode, but it may interfere with navigation (Howard et al., 1983) or provide 
a portal of entry for bacterial infection García Hartmann, 1997). Although S. minor infestation in auditory organ was suspected to play a part in some cetacean strandings, their role remains unresolved (Measures, 2001).

Pyloric stenosis due to chronic gastritis associated with Pholeter gastrophilus, as observed in this study, was regarded as the cause of death in a dolphin by Kirkwood et al. (1997). However, gastric nodules caused by trematodes, frequently observed in the stomach wall of cetaceans, are apparently of little pathological consequence (Baker, 1992; Baker and Martin, 1992; Siebert et al., 2001).

As seen in this study, Campula oblonga infestation frequently produces local hepatic fibrosis and chronic cholangitis. It has a high prevalence in bycaught porpoises (Benke et al., 1998).

Entanglement in fishing nets seemed a less important cause of death in our investigations than in studies from other countries bordering the North Sea (Baker and Martin, 1992; Kuiken et al., 1994; Kirkwood et al., 1997; Benke et al., 1998; Siebert et al., 2001). The annual average number of porpoises dying in Danish gill nets between 1994 and 1998 was 6785 (Vinther, 1999). The average percentage of stranded porpoises showing signs of net entanglement was $34 \%$ on the British coasts from 1990 to 1996 (Jepson et al., 2000), 50\% on the German coasts from 1991 to 1993 (Benke et al., 1998), $10-20 \%$ on the Dutch coast from 1990 to 1994 (Addink and Smeenk, 1999), and 24\% for the French part of the Channel from 1970 to 1994 (A. Collet, unpublished data). In our study, only four porpoises were brought back by fishermen, but following Kuiken's (1996) criteria for death due to entanglement in fishing nets, we identified four additional by-caught porpoises. Such a level (8/ 55) was similar to that reported in the Netherlands. The difference between this study and those in other countries bordering the North Sea, where by-catch is considered to be the main threat for cetaceans, may be due to different fishery practices. Indeed, the use of gill nets is relatively infrequent in Belgium and the Netherlands (Reijnders et al., 1996). Beyond the territorial limits, however, Dutch and Belgian waters are intensively used by gill net fishermen from other European nations, especially France, Denmark and the United Kingdom. The prevalence of by-catch, if based only on the number of porpoises reported by fishermen, would be largely underestimated in the southern North Sea. According to Siebert et al. (2001), by-catches probably have a significant impact on the population dynamics of North Sea porpoises.

One porpoise had a fractured rib with severe acute exudative pleurisy but without evidence of other lesions. Rib fractures in porpoises are consistent with attacks from bottlenose dolphins (Jepson and Baker, 1998), but they are usually accompanied by other traumatic lesions (Jepson $e t$ al., 2000).

Upper digestive tract ulcers have been reported frequently in stranded porpoises (Baker and Martin, 1992; Kennedy et al., 1992a,b) and other cetaceans (Domingo et al., 1992; De Guise et al., 1995; Jauniaux et al., 1998). A specific aetiology has not been identified for mouth or oesophageal ulcers and it has been suggested that such lesions could be related to debilitating disease (Sweeney and Ridgway, 1975). As PAS staining was negative in all cases examined in this study, isolation of Candida sp. from one oesophageal ulcer is likely to have represented post-mortem contamination. Domingo et al. (1992), who found such lesions in morbillivirus-infected dolphins, attributed them to secondary opportunistic agents or to calicivirus, herpesvirus or picornavirus infections. Oesophageal ulcers have also been reported in beluga whales (De Guise et al., 1995) seropositive for herpesvirus. Antibodies to herpesvirus were also detected, however, in sera of animals without lesions (Mikaelian et al., 1999).

Macroscopically visible thymic cysts, similar to those observed in an adult male in this study, have been reported previously in only seven harbour porpoises, in which they may have arisen from degenerating Hassal's corpuscules or condensed epithelial reticulum (Wünschmann et al., 1999a).

Adrenal hyperplasia, observed in one adult in this study, may be aetiologically related to xenobiotics in seals (Bergman and Olsson, 1985), but such a relationship has not been established for porpoises (Kuiken et al., 1993).

Infectious diseases may be related to high tissue concentration of organochlorines (Jepson et al., 1999) or mercury (Siebert et al., 1999), frequently reported in porpoises from other parts of the North Sea. Nevertheless, such an association was not always confirmed (Kuiken et al., 1994).

A surprising observation in the present study was a recent rise in strandings. Indeed, in 1999, more porpoises were available for examination than in the entire previous 9 -year period. There was no evidence to suggest that a viral infection was the cause of the increased mortality. Moreover, the majority of carcasses showed no signs of net entanglement. However, the number of porpoises in the southern North Sea may have increased, as indicated by increased sightings at sea and a recent rise in strandings in the Channel, an area in which 
porpoises were previously rare (Van Canneyt, personal communication). It seems more likely that such an increase would have resulted from a distribution shift rather than a recent rise in the local sub-population, because the ratio of juveniles to adults in our series was not modified. As reported by Addink and Smeenk (1999), changes in the abundance of odontocetes in certain regions may be related to the abundance of prey.

The area covered by this study extended from the Scheldt estuary to the bay of the Somme (Fig. $1)$. This is no more than a small section $(200 \mathrm{~km})$ of the entire North Sea coastline. It represents, however, a narrow and shallow part of the North Sea, which possibly encourages the concentration of marine mammals as their circulate through the Channel, thereby increasing the numbers of drifting carcasses that come ashore.

\section{Acknowledgments}

The authors thank Centre de Recherche sur les Mammifères Marins (La Rochelle, France), the volunteers and the Céto-club who helped us to collect and necropsy porpoises. We also acknowledge M. Domingo for providing tissues of a morbillivirus-infected dolphin, A. Trudgett for the monoclonal antibody to the phocine distemper virus, and A. Villers, M. Sarlet, M. P. Desmecht and F. Verdebout for technical assistance. This work was funded by the Belgian State - Prime Minister's Service, Office for Scientific, Technical and Cultural Affairs (MN/DD/51).

\section{References}

Addink, M. and Smeenk, C. (1999). The harbour porpoise Phocoena phocoena in Dutch coastal waters: analysis of stranding records for the period 1920-1994. Lutra, 41, 55-79.

Appel, M. and Robson, D. S. (1973). A microneutralization test for canine distemper virus. American Journal of Veterinary Research, 34, 1459-1463.

Baker, J. R. (1992). Causes of mortality and parasites and incidental lesions in dolphins and whales from British waters. Veterinary Record, 130, 569-572.

Baker, J. R. and Martin, A. R. (1992). Causes of mortality and parasites and incidental lesions in harbour porpoises (Phocoena phocoena) from British waters. Veterinary Record, 130, 554-558.

Benke, H., Siebert, U., Lick, R. R., Bandomir, B. and Weiss, R. (1998). The current status of harbour porpoises (Phocoena phocoena) in German waters. Archives of Fisheries and Marine Research, 46, 97-123.

Bergman, A. and Olsson, M. (1985). Pathology of Baltic grey seal and ringed seal females with special reference to adrenocortical hyperplasia: is environmental pollution the cause of a widely distributed disease syndrome? Finnish Game Research, 44, 47-62.

Brattey, J. and Stenson, G. B. (1995). Helminth parasites of the alimentary tract of the harbor porpoise, Phocoena phocoena (L.), from Newfoundland and Labrador. Journal of the Helminthological Society of Washington, 62, 209-216.

De Guise, S., Lagace, A., Beland, P., Girard, C. and Higgins, R. (1995). Non-neoplastic lesions in beluga whales (Delphinapterus leucas) and other marine mammals from the St Lawrence estuary. Fournal of Comparative Pathology, 112, 257-271.

Domingo, M., Visa, J., Pumarola, M., Marco, A. J., Ferrer, L., Rabanal, R. and Kennedy, S. (1992). Pathologic and immunocytochemical studies of morbillivirus infection in striped dolphins (Stenella $\mathrm{co}^{-}$ eruleoalba). Veterinary Pathology, 29, 1-10.

García Hartmann, M. (1997). Pathology of marine mammals. In: Marine Mammals, Seabirds, and Pollution of Marine Systems, T. Jauniaux, F. Coignoul, and J.-M. Bouquegneau, Eds, Presses de la Faculté de Médecine Vétérinaire, Liège, pp. 117-149.

Howard, E. B., Britt, J. O. and Matsumodo, G. (1983). Parasitic diseases. In: Pathobiology of Marine Mammal Diseases, E. B. Howard, Ed., CRC Press, Boca Raton, Florida, pp. 119-232.

Jauniaux, T., Boseret, G., Desmecht, M., Haelters, J., Manteca, C., Tavernier, J., Van Gompel, J. and Coignoul, F. (2001). Distemper in common seals (Phoca vitulina) stranded on the coasts of Belgium and northern France during summer 1998. Veterinary Record, 148, 587-591.

Jauniaux, T., Brosens, L., Jacquinet, E., Lambrigts, D., Addink, M. J., Smeenk, C. and Coignoul, F. (1998). Postmortem investigations on winter stranded sperm whales from the coasts of Belgium and the Netherlands. Fournal of Wildlife Diseases, 34, 99-109.

Jauniaux, T., Charlier, G., Desmecht, M., Haelters, J., Jacques, T., Losson, B., Van Gompel, J., Tavernier, J. and Coignoul, F. (2000). Pathological findings in two fin whales (Balaenoptera physalus) with evidence of morbillivirus infection. Fournal of Comparative Pathology, 123, 198-201.

Jepson, P. D. and Baker, J. R. (1998). Bottlenosed dolphins (Tursiops truncatus) as a possible cause of acute traumatic injuries in porpoises (Phocoena phocoena). Veterinary Record, 143, 614-615.

Jepson, P. D., Baker, J. R., Kuiken, T., Simpson, V. R., Kennedy, S. and Bennett, P. M. (2000). Pulmonary pathology of harbour porpoises (Phocoena phocoena) stranded in England and Wales between 1990 to 1996. Veterinary Record, 146, 721-728.

Jepson, P. D., Bennett, P. M., Allchin, C. R., Law, R. J., Kuiken, T., Baker, J. R., Rogan, E. and Kirkwood, J. K. (1999). Investigating potential associations between chronic exposure to polychlorinated biphenyls and infectious disease mortality in harbour porpoises from England and Wales. Science of the Total Environment, 243/244, 339-348.

Kennedy, S., Kuiken, T., Ross, H. M., McAliskey, M., Moffett, D., McNiven, C. M. and Carole, M. (1992a). 
Morbillivirus infection in two common porpoises (Phocoena phocoena) from the coasts of England and Scotland. Veterinary Record, 131, 286-290.

Kennedy, S., Lindstedt, I. J., McAliskey, M., McConnell, S. and McCullough, S. J. (1992b). Herpesviral encephalitis in a harbour porpoise (Phocoena phocoena). Gournal of Zoo and Wildlife Medicine, 23, 374-379.

Kennedy, S., Smyth, J. A., Cush, P. F., McAliskey, M., McCullough, S. J. and Rima, B. K. (1991). Histopathological and immunocytochemical studies of distemper in harbour porpoises. Veterinary Pathology, 28, $1-7$.

Kirkwood, J. K., Bennett, P. M., Jepson, P. D., Kuiken, T., Simpson, V. R. and Baker, J. R. (1997). Entanglement in fishing gear and other causes of death in cetaceans stranded on the coasts of England and Wales. Veterinary Record, 141, 94-98.

Kuiken, T. (1996). Review of the criteria for the diagnosis of by-catch in cetaceans. In: Diagnosis of Bycatch in Cetaceans, Proceedings of the second European Cetacean Society workshop on cetacean pathology, Montpellier, France, 2 March 1994. T. Kuiken, Ed., European Cetacean Society, Saskatoon, p. 38.

Kuiken, T., Bennett, P. M., Allchin, C. R., Kirkwood, J. K., Baker, J. R., Lockyer, C., Walton, M. J. and Sheldrick, M. C. (1994). PCBs, cause of death and body condition in harbour porpoises (Phocoena phocoena) from British waters. Aquatic Toxicology, 28, 13-28.

Kuiken, T. and García Hartmann, M. (1991). Proceedings of the first European Cetacean Society workshop on cetacean pathology: dissection techniques and tissue sampling. ECS Newsletter, No. 17, special issue.

Kuiken, T., Höfle, U., Bennett, P. M., Allchin, C. R., Kirkwood, J. K., Baker, J. R., Appleby, E. C., Lockyer, C., Walton, M. J. and Sheldrick, M. C. (1993). Adrenocortical hyperplasia, disease, and chlorinated hydrocarbons in the harbour porpoise (Phocoena phocoena). Marine Pollution Bulletin, 26, 440-446.

Lockyer, C. (1995). Aspects of the morphology, body fat condition and biology of the harbour porpoise, Phocoena phocoena, in British waters. In: Biology of the Phocoenids, A. Bjorge and G. P. Donovan, Eds, International Whaling Commission, Cambridge, pp. 199-209.

Measures, L. N. (2001). Lungworms of marine mammals. In: Parasitic Diseases of Wild Mammals, W. Samuel, M. Pybus, and A. Koca, Eds, Manson, London, pp. 279-300.

Mikaelian, I., Tremblay, M.-P., Montpetit, C., Tessaro, S. V., Cho, H. J., House, C., Measures, L. and Martineau, D. (1999). Seroprevalence of selected viral infections in a population of beluga whales (Delphinapterus leucas) in Canada. Veterinary Record, 144, 50-51.

Müller, G., Siebert, U., Wünschmann, A., Artelt, A. and Baumgartner, W. (2000). Immunohistochemical and serological investigation of morbillivirus infection in harbour porpoises (Phocoena phocoena) from the German Baltic and North Sea. Veterinary Microbiology, 75, $17-25$.

Northridge, S. P., Tasker, M. L., Webb, A. and Williams, J. M. (1995). Distribution and relative abundance of harbour porpoises (Phocoena phocoena L.), white-beaked dolphins (Lagenorhynchus albirostris Gray), and minke whales (Balaenoptera acutorostrata Lacepède) around the British Isles. International Council for the Exploration of the Sea Fournal of Marine Science, 52, 55-66.

Read, A. J. (1999). Harbour porpoise Phocoena phocoena (Linnaeus, 1758). In: Handbook of Marine Mammals, Vol. 6. The Second Book of Dolphins and the Porpoises, S. H. Ridgway and Sir R. Harrison, Eds, Academic Press, San Diego, pp. 323-355.

Reijnders, P. J. H., Leopold, M. F., Camphuysen, C. J., Heessen, H. J. L. and Kastelein, R. A. (1996). The status of the harbour porpoise, Phocoena phocoena, in Dutch waters and the state of related research in the Netherlands: an overview. Report of the International Whaling Commission, 46, 607-611.

Siebert, U., Joiris, C., Holsbeek, L., Benke, H., Failing, K., Freze, K. and Petzinger, E. (1999). Potential relation between mercury concentrations and necropsy findings in cetaceans from German waters of the North and Baltic Seas. Marine Pollution Bulletin, 38, 285-295.

Siebert, U., Wünschmann, A., Weiss, R., Frank, H., Benke, H. and Frese, K. (2001). Post-mortem findings in harbour porpoises (Phocoena phocoena) from the German North and Baltic Seas. Journal of Comparative Pathology, 124, 102-114.

Stroud, R. K. and Roffe, T. J. (1979). Causes of death in marine mammals stranded along the Oregon Coast. Journal of Wildlife Diseases, 15, 91-97.

Sweeney, J. C. and Ridgway, S. H. (1975). Common diseases of small cetaceans. Fournal of the American Veterinary Medical Association, 167, 533-540.

Trudgett, A., Lyons, C., Welsh, M.J., Duffy, N., McCullough, S. J. and McNeilly, F. (1991). Analysis of a seal and a porpoise morbillivirus using monoclonal antibodies. Veterinary Record, 128, 61.

Tryland, M., Kleivane, L., Alfredsson, M., Kjed, M., Arnason, A., Stuen, S. and Godfroid, J. (1999). Evidence of Brucella infection in marine mammals in the North Atlantic Ocean. Veterinary Record, 144, 588-592.

van Bressem, M. F., Jepson, P. D. and Barrett, T. (1998). Further insight on the epidemiology of cetacean morbillivirus in the Northeastern Atlantic. Marine Mammal Science, 14, 605-613.

van Nie, C. J. (1989). Postmortem findings in stranded harbour porpoises (Phocoena phocoena) in The Netherlands from 23rd March 1983 to 25th June 1986. Aquatic Mammals, 15, 80-83.

Vinther, M. (1999). Bycatches of harbour porpoises (Phocoena phocoena L.) in Danish set-net fisheries. Fournal of Cetacean Research and Management, 1, 123-135.

Wünschmann, A., Siebert, U. and Frese, K. (1999a). Thymic cysts in harbor porpoises (Phocoena phocoena) from the German North Sea, Baltic Sea, and waters of Greenland. Veterinary Pathology, 36, 391-396.

Wünschmann, A., Siebert, U. and Weiss, R. (1999b). Rhizopus mycosis in a harbor porpoise from the Baltic Sea. Fournal of Wildlife Diseases, 35, 569-573.

$$
\left.\begin{array}{c}
\text { Received, Fuly 12th, } 2001 \\
\text { Accepted, December 19th, } 2001
\end{array}\right]
$$

